Journal of Theoretical and Applied Mechanics, Sofia, Vol. 47 No. 4 (2017) pp. 23-36

\title{
EXPERIMENTAL RESEARCH OF ROTATIONAL-AND-FRICTIONAL BORING OF BIG HOLES IN LARGE PARTS
}

\author{
K.T. SHEROV ${ }^{1}$, M.R. SiKhimbaYeV ${ }^{2 *}$, B.S. DonenbaYeV ${ }^{1}$, \\ A.A. SAGitov ${ }^{1}$, S.S. AinABEKOVA ${ }^{1}$ \\ ${ }^{1}$ Karaganda State Technical University, B. Mira str. 56, 100027, \\ Karaganda, Kazakhstan \\ ${ }^{2}$ Karaganda Economic University, Akademicheskaya str., 9, 100009, \\ Karaganda, Kazakhstan
}

[Received 29 may 2017. Accepted 4 December 2017]

\begin{abstract}
When producing large-dimensional parts of heavy machines, the largest specific weight in the general labour input is made by the operations, connected with machining the main holes, i. e. holes of large diameter. To the holes of large diameter of large-dimensional parts, there are specified high requirements in the aspect of accuracy of the size, shape and arrangement. Machining of holes still remains one of the topical problems of present day mechanical engineering, in particular machine-building enterprises of the Republic of Kazakhstan.
\end{abstract}

Solving the problem of ensuring accuracy and quality of machining large holes of large-dimensional parts requires the development of new resource-saving technologies of machining. In this work there are presented the results of studying a resource-saving method of rotation-friction boring of large diameter holes. There has been achieved good results in providing the quality indicators, when machining by the proposed method of rotation-friction boring with the use of the tool (a disk cutter) made of steel $90 \mathrm{CrSi} 5$ in comparison with well-known boring of holes. The diagram of chip formation of cutting and the results of studying the zone of chip formation by the metallographic method is also presented.

KEY WORDS: Rotation-friction boring, angle of setting, chip crushing, deformation, chip formation, boring holes, large-dimensional parts, large diameter holes, roughness, hardness

\section{INTRODUCTION}

At present, manufacturing the machining equipment for mining, oil, coal, and other industries of the Republic of Kazakhstan (RK) is generally provided by the use of

\footnotetext{
${ }^{*}$ Corresponding author e-mail: smurat@yandex.ru
} 
metals and alloys with special physical-mechanical characteristics. The majority of basic parts of the machining equipment for the mining industry are made of these materials and have large diameter holes, which machining is a topical problem. Since these holes are generally made by boring, it requires the additional production of the tooling. In general, this operation consists of two steps: rough boring and fine boring. With big sizes of holes it is troublesome to ensure accuracy, and sometimes it is quite difficult to provide it. This is connected with the emergence of great vibrations and complexity of the interconnected accurate setting of the tooling. When machining big holes, besides improving the quality and accuracy, it is necessary to provide decreasing the cost of the part production. At present, the problem of ensuring accuracy and quality of machining big holes remains not solved.

It is known that a great reserve of increasing productivity of the process, improving the quality of the machined surfaces is put in the methods of rotational cutting, in which the cutting elements are cut tools rotating in the course of cutting around the axes. The basic feature of rotational cutting is sharp decreasing speeds of the working surfaces of the tool sliding relative to the machined material, without reducing the speed of the tool and the part relative movement, by replacing sliding friction in the contact zones with rolling friction [1].

However, this method has not found broad application in production, because of the high cost of producing the cut tool, which is entirely made of instrumental materials (quick cutting steels, hard alloys). Besides, at chips or wear it is necessary to replace or to regrind the cut tool. Regrinding the cut tool is a labour intensive process, as well as its production.

The main difference of the developed method of rotational and frictional turning of external cylindrical surfaces is using a special rotational and frictional cut tool made of non-instrumental material. When developing new methods of machining by cutting the study and investigation of the chip formation process has both scientifictheoretical and practical value. The cutting process represents a number of extremely complex phenomena, depending on physical-and-mechanical properties of the machined material, which is followed by plastic and elastic deformations, destruction, friction and heat emission.

Studying the cut-off layer at rotational and frictional turning is also of scientific and practical interest. It is known, that the errors of the part shape, caused by the part and the tool warming up can be calculated as we know the temperature of the part and the tool for what, it is necessary to have the data of the thermal phenomena, accompanying the transformation of the cut-off layer into chips [2,3]. The assignment of the cutting modes is impossible without knowing the fundamental laws of physics of the cutting process, which are based on the processes happening in the zone of deformation and on the contact surfaces of the tool. 
The cut-off layer is exposed to compression under the impact of the cutting tool. The process of compression, when cutting differs from the usual compression of a specimen, taken between two approaching surfaces in the fact that the cut-off layer is connected with the other lot of the work piece.

At the same time, the forward side of the cutter, that makes pressure upon metal forms in the small zone ahead of the cutter, an originally complex elastic strained state that transforms in the course of the cutter advancing into plastic deformation. The latter extends distinctly in the zone that is limited by the surface located under some angle $\beta_{1}$. Under some conditions of cutting, for example, when machining fragile, hard or strongly strain-hardening metals, the chip shear and even the complete chip element shearing occur along this plane of shear. Some researchers state that in the metal cutting zone elementary volumes of the cut-off layer are exposed to uniform all-round compression and at the same time experience tangent stresses [4,5].

Ease with which metal deformation takes place depends strongly on how the direction of acting forces coincides with the direction of the plane of possible shear. Deformation is facilitated when the cutting-off force is parallel to the shear plane. Usually the shear happens in the plan that is perpendicular to the spatial diagonal of the cube. Some researchers consider that the angle of shear $\beta_{1}$ is of great importance for the cutting process, because its value defines the chip shrinkage, i.e. the removed layer deformation with all the implied consequences [2,3].

Recently, there have been developed different methods of cutting, when machining difficult to machine and high-strength materials, in particular methods of machining using the tools with self-rotating cutters. There have also been realized a number of methods of traditional rotational machining, but the scheme of cutting and the used tools have not provided a great difference of the cut-off layer deformation $[4,6]$.

Due to the aforesaid, the work aimed at studying the mechanism of chip formation, the strained state of the machined material and the cut-off layer, as well as the regularities and the phenomena, occurring in the course of rotational and frictional turning is a topical task. In this regard, the work aimed at the development and the implementation of resource-saving technologies for machining, one type of which is rotational-friction turning.

Thus, the problem of machining large diameter holes can be solved by developing new resource-saving methods of machining and progressive designs of cutting tools, that improve the accuracy and the quality of machining.

Due to the aforesaid, scientific studies aimed at developing a resource-saving method of machining with the use of rotational-and-frictional boring are topical. It should be noted, that the basis for research and development of this method was the results obtained by the authors on the study of resource-saving methods of thermo friction processing at low speeds [7-9]. 


\section{Methodology of CARrying out The Studies And THE USED EQUIPMENT}

The tasks defined in the work have been solved by experimental methods. In theoretical studies there have been used basic provisions of the technology of mechanical engineering, theory of cutting materials, technology of metals. For studying chip formation, there has been used the metallographic method. When measuring the quality indicators of the machined surfaces there have been used up-to-date methods of measuring by means of automatic devices. Experimental studies have been carried out in the laboratory of the "Machining Equipment, Mechanical Engineering and Standardization" department of Karaganda State Technical University. For the experimental study of machining by rotational-and-frictional turning there has been prepared a sample: a blank made of steel 35L. The sample has been machined on the JET GH-1640ZX turning screw cutter.

In Fig. 1 there is shown a photograph of the JET GH-1640ZX turning screw cutter.

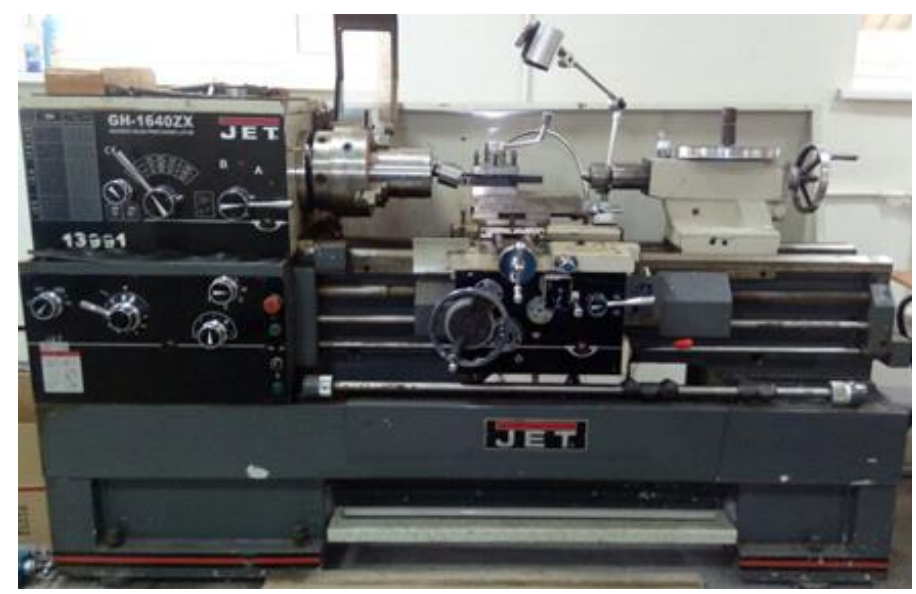

Fig. 1. JET GH-1640ZX turning screw cutter photograph.

In Fig. 2 there is shown a photograph of the rotational-and-frictional tool for machining big holes.

Measuring the machined surface roughness and hardness has been carried out by means of electronic devices. In Fig. 3 there are shown devices for measuring the surface roughness and hardness.

For metallographic studies of chips, there has been used the universal metallographic microscope Altami MET 5T. In Fig. 4 there is shown the universal metallographic microscope Altami MET 5T. 


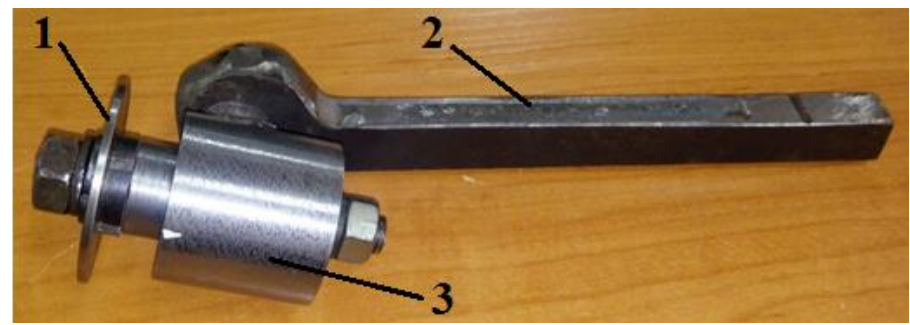

Fig. 2. Rotational-and-frictional tool for machining big holes photograph: 1 - disk cutter made of steel $90 \mathrm{CrSi} 5 ; 2$ - rotational-and-frictional tool handle; 3 - rotational-and-frictional tool case.

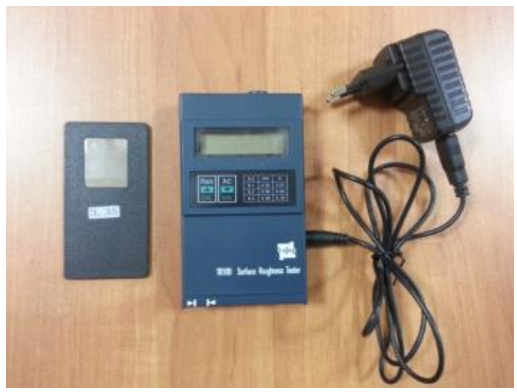

(a)

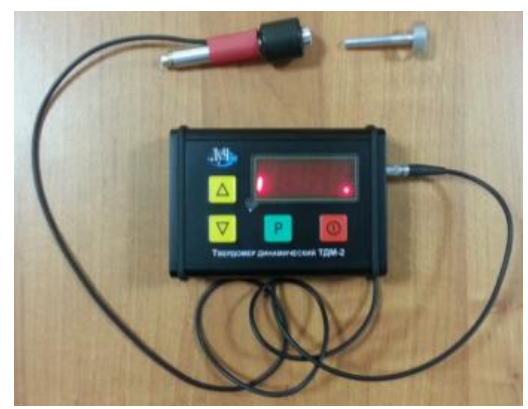

(b)

Fig. 3. Devices for measuring the surface roughness and hardness: (a) - portable roughness meter (profile meter) TR 100; (b) - small-sized dynamic durometer TDM-2.

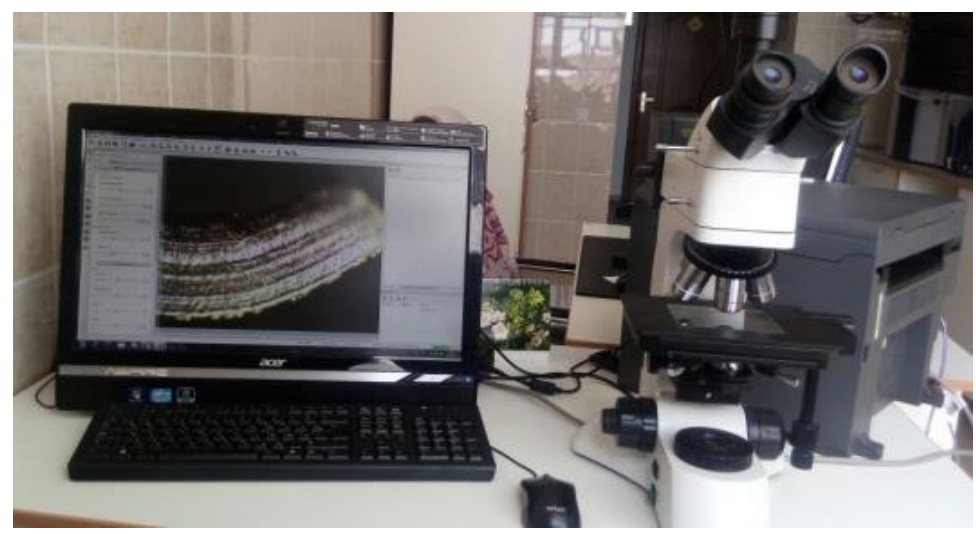

Fig. 4. Universal metallographic microscope Altami MET 5T.

\section{EXPERIMENTAL STUDIES AND DISCUSSING THE RESULTS}

For carrying out experimental studies, there has been prepared a sample: a blank of the cylinder mouth case. Its photograph is shown in Fig. 5. 


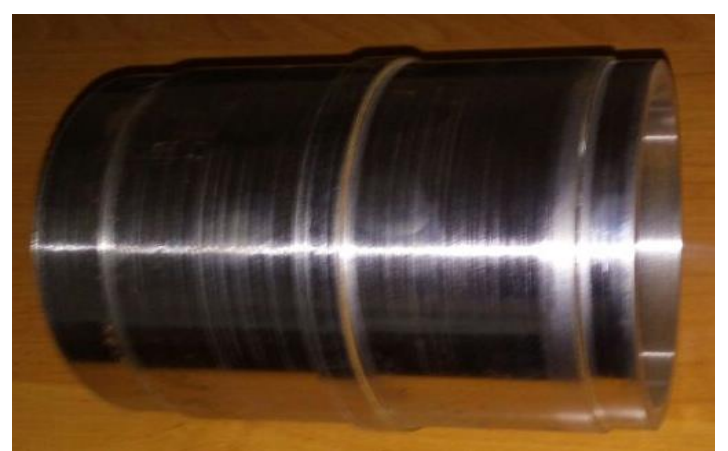

(a)

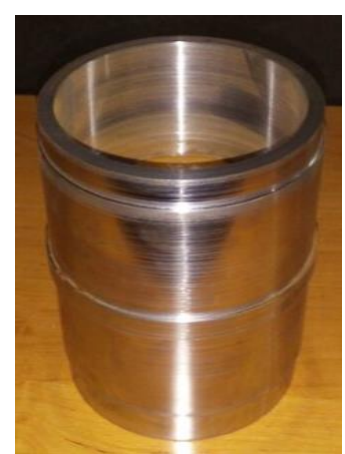

(b)

Fig. 5. Cylinder mouth case photograph: (a) - side view; (b) - top plan view.

The material for the cylinder mouth case is steel 35L. Overall dimensions: external Ø $278 \mathrm{~mm}$, internal Ø $230 \mathrm{~mm}$, length $520 \mathrm{~mm}$.

In Fig. 6 there is shown the process of machining the cylinder mouth case.

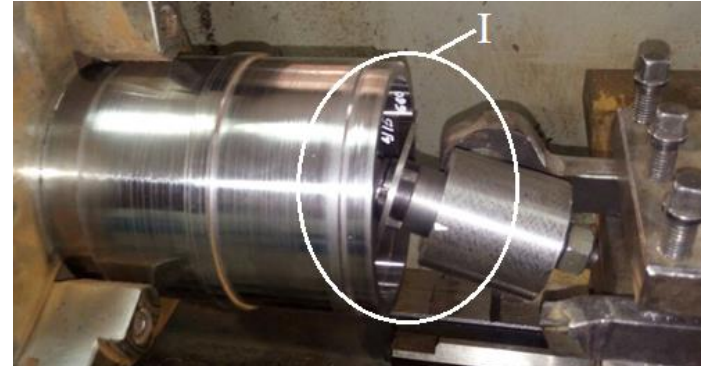

(a)

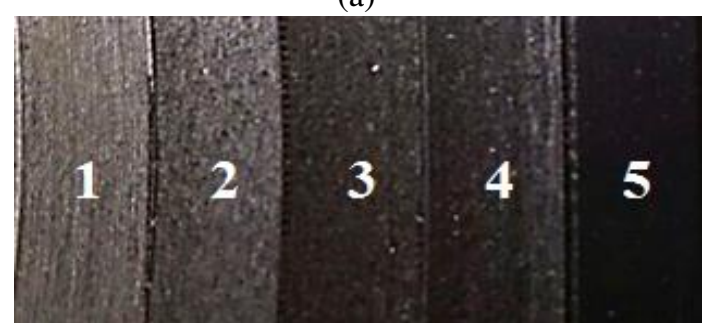

(b)

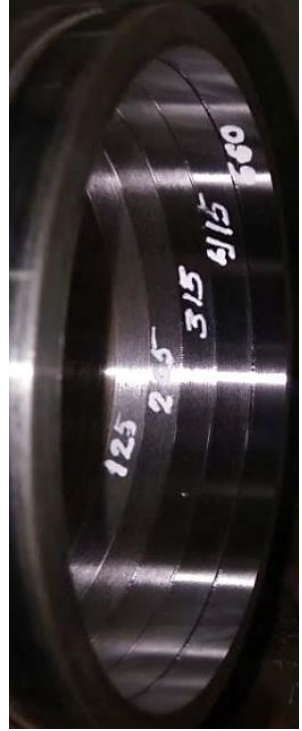

(c)

Fig. 6. Process of machining the cylinder mouth case: (a) - boring process; (b) - machine surfaces roughness: 1 - at $n=125 \mathrm{rpm} ; 2$ - at $n=235 \mathrm{rpm} ; 3$ - at $n=315 \mathrm{rpm} ; 4$ - at $n=415 \mathrm{rpm} ; 5-$ at $n=660 \mathrm{rpm}$; (c) - enlarged image of the machine hole surfaces at various speeds of cutting. 
Machining by rotational-and-frictional boring has been carried out in the following modes of cutting: $S=0.14 \div 0.45 \mathrm{~mm} / \mathrm{rev} ; n=125 \div 660 \mathrm{rpm} ; t=1 \mathrm{~mm}$; $\beta=5^{\circ} \div 35^{\circ}$. The results show, that in case of correctly selected modes of cutting and in particular the correct selection of the tool setting angle, it is possible to provide the necessary conditions for implementing the process of cutting by rotational-andfrictional boring.

In Fig. 7 there are shown diagrams of dependence of the machined surfaces roughness and hardness on the spindle rotation speed $n$ at various values of feed $S$.

(a)

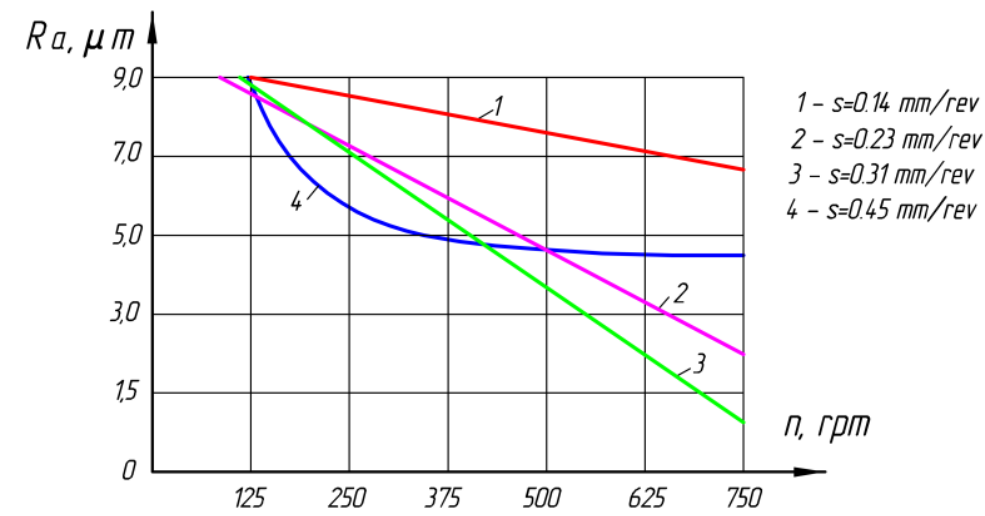

$H B, \mathrm{kgf} / \mathrm{mm}^{2}$

(b)

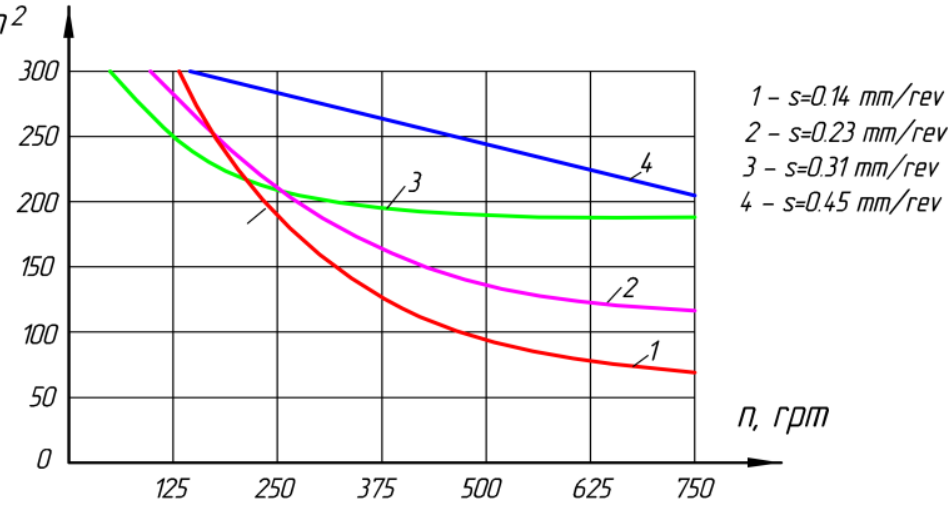

Fig. 7. Dependences of the machined surface roughness and hardness on the spindle rotation speed at various values of feed: (a) - diagram of the spindle rotation speed impact on the machined surface roughness at various values of feed; (b) - diagram of the spindle rotation speed impact on the machines surface hardness at various values of feed: $S=0.31 \mathrm{~mm} / \mathrm{rev}$; $t=1 \mathrm{~mm} ; \beta=15^{\circ}$.

There has been experimentally studied the impact of the rotational-and- frictional tool setting angle $\beta$ on the machined surface. In Fig. 8 there is shown the diagram of the machined surface roughness dependence on the spindle rotation speed at various values of the setting angle $\beta$. 


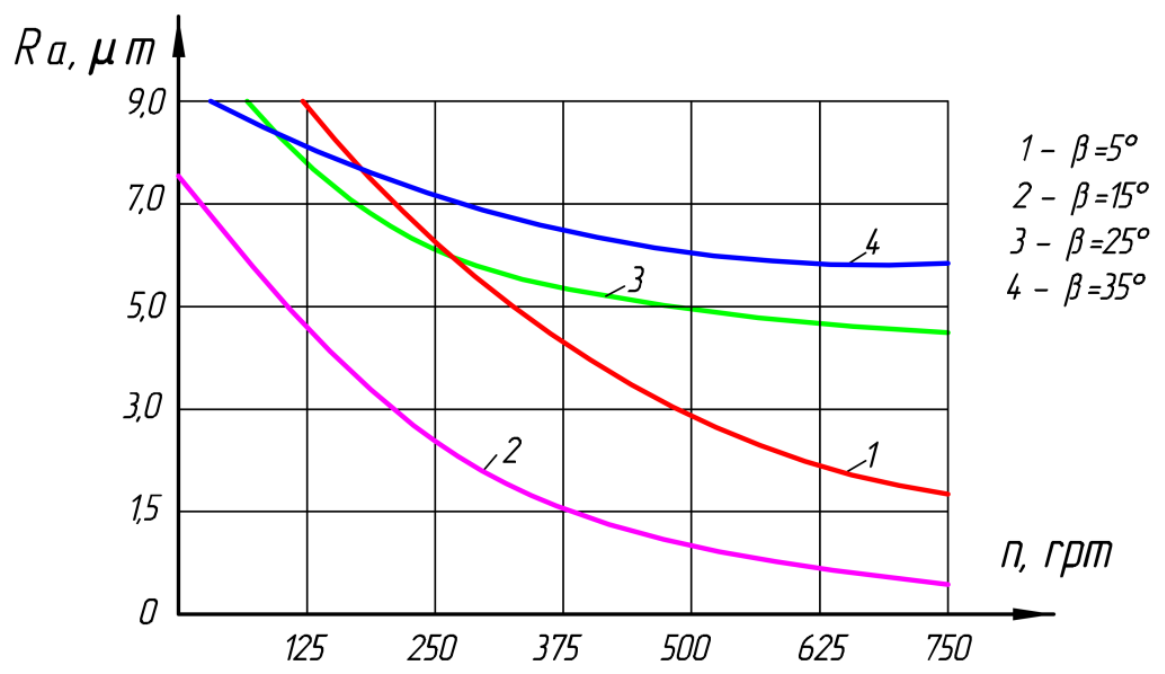

Fig. 8. Dependence of the machined surface roughness on the spindle rotation speed at various values of the rotational-and-frictional tool setting angle $\beta(S=0.31 \mathrm{~mm} / \mathrm{rev} ; t=1 \mathrm{~mm})$.

The obtained results permit to state achieving high rates of the quality, when machining by the proposed method of rotational-and-frictional boring with the use of the tool (a disk cutter), made of steel $90 \mathrm{CrSi} 5$ in comparison with the traditional boring a hole (in case of traditional fine boring it is possible to provide class 4-7 of roughness $\left(R_{a}=6.3 \div 0.63 \mu \mathrm{m}\right)$, and in case of thin boring class $8-10$ of roughness $\left(R_{a}=0.63 \div 0.08 \mu \mathrm{m}\right)[10]$.

It has been established, that cutting speed increase impacts positively the indicators of the machined surface quality. The optimum modes for machining steel 35L in the proposed method of rotational-and-frictional boring are: $S=0.31 \mathrm{~mm} / \mathrm{rev}$, $n_{s p}=660 \mathrm{rpm}, t=1 \mathrm{~mm}, \beta=15^{\circ}$.

When machining with optimum modes of cutting, there has been obtained the surface roughness 5 (see Fig. 6, (b)) that corresponds to $R_{a}=0.8 \mu \mathrm{m}$ (see Fig. 7, (a)). The results of the study have shown that, when selecting the optimum modes of cutting, it is possible to operate the quality indicators.

The obtained results (see Figs. 7 and 8$)$ of the machined surface roughness $\left(R_{a}=\right.$ $6.3 \div 0.8 \mu \mathrm{m}$ ) show the possibility of replacing traditional boring with the cutters equipped with plates, made of hard alloys by the proposed rotational-and- frictional boring with the use of the tool (a disk cutter) made of steel 90CrSi5. The results of the multifactorial experiment were processed according to the program "ANETR-5" [11]. The method is universal, both in the part of the field of the application and in variants of constructing models: models can have the form of a sum, products 
of particular dependences, their combinations, with sequential neutralization of the influence of priority arguments and without it. An important advantage of the method is the possibility with an appropriate level of reliability to evaluate the influence of those arguments, that in traditional methods will be excluded from the analysis, as not affecting the objective function significantly (for example, by the Fisher criterion).

Table 1. Processing parameters and their levels

\begin{tabular}{lcccc}
\hline \hline Factors & Level 1 & Level 2 & Level 3 & Level 1 \\
\hline Spindle rotation speed $(n)[\mathrm{rpm}]$ & 125 & 265 & 415 & 660 \\
Feed $(S)[\mathrm{mm} / \mathrm{rev}]$ & 0.14 & 0.23 & 0.31 & 0.45 \\
Tool setting angle $(\beta)$ & 5 & 15 & 25 & 35 \\
\hline
\end{tabular}

Table 2. The plan of the three-factor experiment

\begin{tabular}{ccccc|ccccc}
\hline \hline $\begin{array}{c}\text { Experiment } \\
\text { number }\end{array}$ & $n$ & $S$ & $\beta$ & $R_{a}$ & $\begin{array}{c}\text { Experiment } \\
\text { number }\end{array}$ & $n$ & $S$ & $\beta$ & $R_{a}$ \\
\hline 1 & 125 & 0.14 & 15 & $6.9(8.4)$ & 9 & 415 & 0.14 & 35 & $7.2(6.1)$ \\
2 & 125 & 0.23 & 25 & $8.4(8.2)$ & 10 & 415 & 0.23 & 5 & $4.7(4.2)$ \\
3 & 125 & 0.31 & 35 & 8.6 & 11 & 415 & 0.31 & 15 & $3.0(4.4)$ \\
4 & 125 & 0.45 & 5 & $9(7.1)$ & 12 & 415 & 0.45 & 25 & $5.0(4.8)$ \\
5 & 265 & 0.14 & 25 & $7.3(7.0)$ & 13 & 660 & 0.14 & 5 & $4.5(3.6)$ \\
6 & 265 & 0.23 & 35 & $7.1(6.9)$ & 14 & 660 & 0.23 & 15 & $1.9(3)$ \\
7 & 265 & 0.31 & 5 & $6.5(5.4)$ & 15 & 660 & 0.31 & 25 & $3.4(3.7)$ \\
8 & 265 & 0.45 & 15 & $4.1(5.6)$ & 16 & 660 & 0.45 & 35 & $5.2(4.2)$ \\
\hline
\end{tabular}

Mathematical model:

$$
R_{a}=\frac{1}{A+B n}+\frac{C}{S}+D \mathrm{e}^{K \beta}
$$

where $A=8.80084 \times 10^{-2}, B=2.71139 \times 10^{-4}, C=1.70656 \times 10^{-1}, D=$ $4.8352, K=8.02792 \times 10^{-3}, L=-6.52267$.

The obtained mathematical model, connecting the spindle speed $(n)$, the feed $(S)$ and the tool mounting angle, allows controlling the surface quality parameters of a large diameter hole and determining the optimal machining modes, ensuring high precision of machining. Using the method of rotational-and-frictional boring when machining big holes of large parts can permit to increase machining productivity in comparison with machining by the cutters equipped with plates made of hard alloys, to provide the required surface roughness, as well as to reduce the cost of producing 


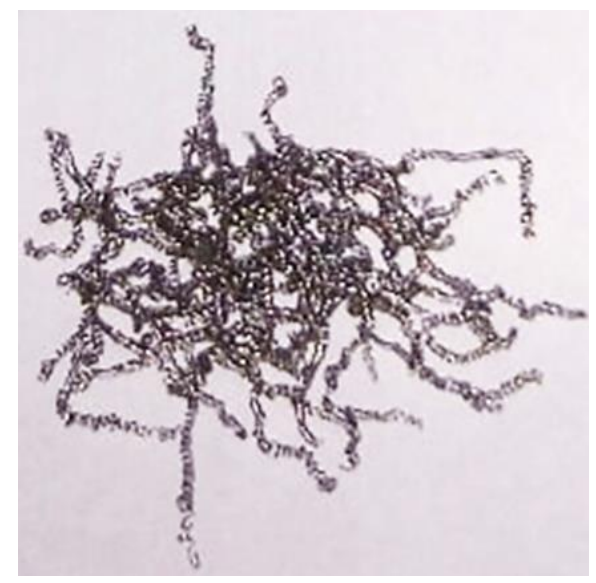

Fig. 9. Spiral flow chips photograph.

a part. In rotational-and-frictional boring holes there are formed spiral flow chips, shown in Fig. 9.

It is known, that the main disadvantage of turning is the absence of chip crushing, which causes additional difficulties in servicing machine tools, in particular when machining blanks made materials forming long chips [12]. In our case, the flow chip in the course of boring has been easily removed and has not rendered any additional problems on machining, for example, on the surface quality. This is explained by the fact, that when machining a blank and the cutting tool are simultaneously in rotation. At this, the direction of the tool rotation is at the angle $\beta$ that promotes chip crushing.

For the metallographic study, there have been prepared sections of the flow chip. In Fig. 10 there are shown microphotographs (magnification $50 \times$ ) of the chip samples texture.

When studying the zone of chip formation it has been established that before the destruction on the shear area (see Fig. 10), in the volume of the chip future element there take place considerable compression deformations, causing the flowing of the cut-off layer material lengthways and perpendicularly to the forward surface. The achievements in the field of mechanics of continuous media permit to study the process of cutting from the position of theory of destruction or cracking [13]. The reasons of forming flow, shearing, granular chips have not finally been found out yet. However, considering cutting as the process of destructing materials, it is possible to estimate the impact of various factors, accompanying the separation of the cut-off layer on the process of forming the superficial layer, the emergence and formation of cracks, etc. 


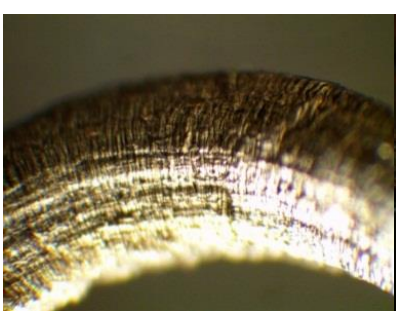

(a)

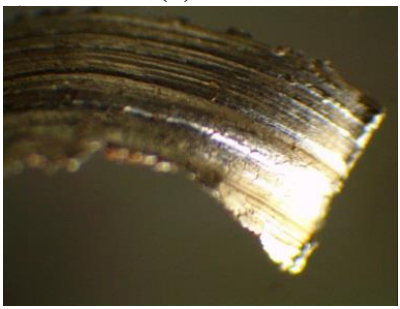

(d)

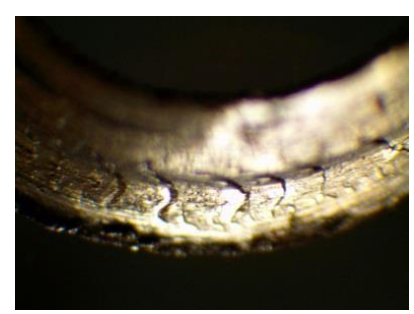

(b)

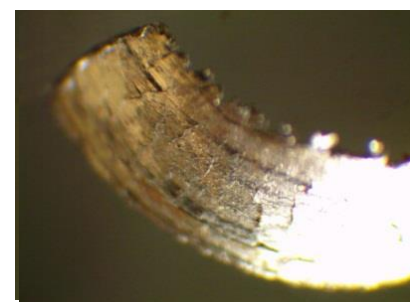

(e)

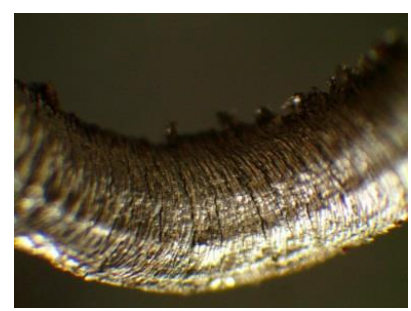

(c)

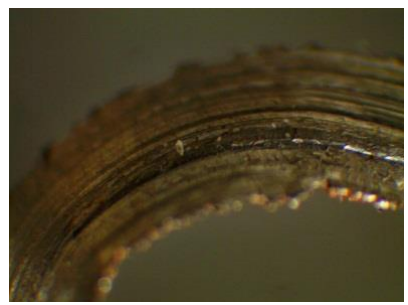

(f)

Fig. 10. Microphotograph (magnification $50 \times$ ) of the chip samples texture.

When introducing the cutting edge in a solid body at its top in the machined material, there appear microcracks that transform into a macrocrack of critical length. The causes of appearing and developing cracks are stretching or shearing stresses, which can be caused by the hydrostatic stress, the bending moment, the existence of a large surface of shear and other factors. In Fig. 11 there is shown the simplest diagram of chip formation, when cutting fragile materials [14]. It is also applicable for our case.

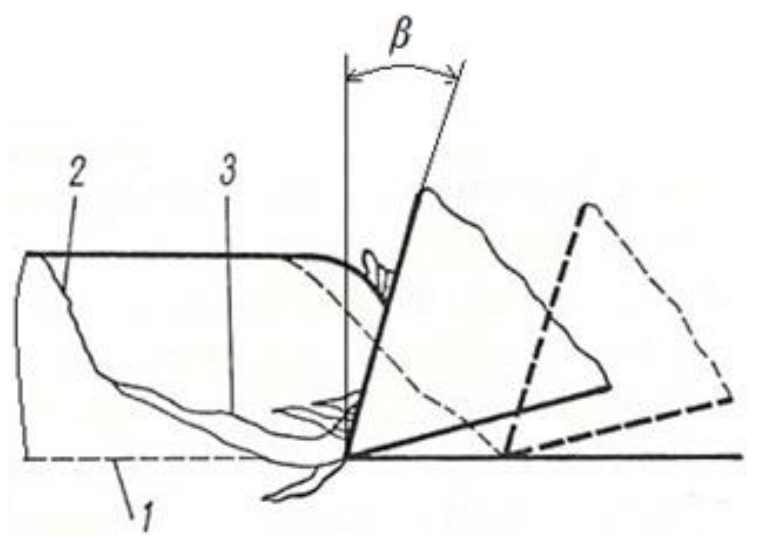

Fig. 11. Diagram of chip formation. 
Under the impact of the cutter (edge) at its forward surface there are formed cracks, extending in the direction of the speed vector. At the first stage of chip formation there takes place a continuous increase in force of cutting, providing the development of a leading uniformly changeable crack 3. It proceeds until chip formation begins to be effected by the bending stress, leading to the fast dropping of the force of cutting and the separation of the chip element on the surface of cutting 2 . At the second stage, there takes place cleaning the surface of cutting 1 , which is characterized by separation of smaller particles of chips, according to the described diagram. If the development of the main crack goes below the surface of cutting, the second stage is not observed.

In our case there can be observed the emergence of microcracks (see Fig. 10). The reason of the emergence of microcracks can be sharp increase in the density of dislocations with the growth of plastic deformations, that leads to the emergence of stretching stresses.

\section{CONCLUSIONS}

Based on the study of producing case-shaped parts in the conditions of machinebuilding enterprises of the Republic of Kazakhstan, it has been revealed that when machining big holes there exists the problem of ensuring accuracy and quality of the machined surface. For solving this problem, there have been studied technological capabilities of the resource-saving method of the rotational-and-frictional boring big holes. The results of experimental studies have shown applicability of the proposed method for boring big holes of large parts.

1. There have been achieved good results for providing the quality indicators, in particular the machined surface roughness of the processed $R_{a}=6.3 \div$ $0.63 \mu \mathrm{m}$ and hardness HB 120-190;

2. The optimum modes of cutting in rotational-and-frictional boring for steel $35 \mathrm{~L}$ are set: $S=0.31 \mathrm{~mm} / \mathrm{rev}, n_{s p}=660 \mathrm{rpm}, t=1 \mathrm{~mm}, \beta=15^{\circ}$.

3. It has been established that when selecting the optimum modes of cutting it is possible to operate the quality indicators.

4. There has been observed flow chip formation, that in the course of boring has easily been removed, and has not rendered any problems on machining or effected the surface quality. This is explained by the fact, that in the process of machining on the blank and the cutting tool are in simultaneous rotation. At this, the direction of the tool rotation is at the angle $\beta$ that promotes chip crushing. 
5. Metallographic studies of chip formation have shown that the temperature in the zone of cutting did not exceed the temperature of the machined material recrystallization. It is supposed, that in the cutting zone the process of deformation is close to isothermal as the warmth, which is emitted in the deformation zone during deformation is almost completely taken away from this zone to the interfaced areas of metal and does not cause heating the deformable layers.

6. There has been experimentally proved the possibility of replacing traditional boring by the cutters, equipped with plates, made of hard alloys by the proposed rotational-and-frictional boring with the use of the tool (a disk cutter) made of steel $90 \mathrm{CrSi} 5$.

7. Using the "ANETR-5" program, a mathematical model has been obtained, which allows to determine in advance the surface roughness before processing.

The use of the method of rotational-and-frictional boring, when machining big holes of large parts can permit to increase the machining productivity in comparison with machining by the cutters, equipped with plates, made of hard alloys, to provide the required surface roughness, to reduce the cost of the part manufacturing.

\section{REFERENCES}

[1] Konovalov, E. G., V. A. Sidorenko, A. V. Soush. Progressive Schemes of Rotational Cutting of Metals, Minsk, Science and Technology, 1982, 272p.

[2] VILner, G. S. To the Problem of Determining the Shear Angle when cutting Metals, Proceedings of High Schools, Mechanical Engineering, 2000, No. 5-6, 95-100.

[3] WiLner, G. S. Mechanism of the Formation of a Hardened Surface Layer in the Processing of Metal by cutting, Technology of Mechanical Engineering, All-Russian Institute of Scientific and Technical Information No. 6, Moscow, 2001, p. 6.

[4] Kushnazarov, I. K., F. Ya. Yakubov, D. T. Khodzhibergenov. Features of the Chip Formation Process in Multi-blade Rotary Machining, Materials of Theoretical and Technical Conference "ISTIQLOL-4", Navoi, Publishing House of OKPP, 1995, 138-139.

[5] Odintsov, P. G., V. N. Dzegylenok. The Main Directions of improving the Methods of Plastic Deformation Surface, Moscow, 1990, 263p.

[6] Konovalov, YE. G. Basics of New Ways of Metal Working, Minsk, AN BSSR, 1981, $298 \mathrm{p}$.

[7] Alyzhanov, M. K., M. R. Sikhimbayev, S. B. Kuzembayev, K. T. Sherov, D. R. Sikhimbayeva, T. A. Khanov, T. B. Kurmangaliyev, D. E. Elemes, B. S. Donenbayev, M. M. Musaev, T. M. Buzauova. Optimization of the Conditions of Convective drying of Thermosensitive Materials. Journal of Theoretical and Applied Mechanics, Sofia, 46 (2016), No. 4, 76-84. 
[8] Sherov, K. T., M. R. Sikhimbayev, A. K. Sherov, B. S. Donenbayev, A. K. Rakishev, A. B. Mazdubai, M. M. Musayev, A. M. Abeuova. Matematical Modelling of Thermofrictional Milling Process using ANSYS WB Software. Journal of Theoretical and Applied Mechanics, Sofia, 47 (2017), No. 2, 24-33.

[9] Sherov, K. T., M. R. Sikhimbayev, M. M. Mussaev, A. K. Rakishev, B. S. DONENBAYEV. Experimental Study of Turn-milling Process using Special Friction Mill made of Steel HARDOX. Metallurgical and Mining Industry, 11 (2016), 52-59.

[10] Yegorov, M. Ye., V. I. Dementyev, V. L. Dmitryev. Technology of Mechanical Engineering, Textbook for Technical Colleges. $2^{\text {nd }}$ ed., add. and rev. - M., Higher School, 1986, 534 p.

[11] Ermekov, M. A., A. A. MaKhov. Statistical-deterministic Method for Constructing Multidimensional Models using a Computer: Textbook, Karaganda, KPTI, 1988, 70 p.

[12] Kravchenko, N. S., V. F. Pegashkin. Analyzing Schemes of Milling, Proc. of the International Scientific and Practical Conference, In 2 v. V. 1. FSAOU VPO "The Ural Federal University n.a. the First President of Russia B. N. Yeltsin”, Nizhnetagil. Technol. Ins. Nizhny Tagil, NTI (branch) URFA, 2015, 51-56.

[13] Klushin, M. I. Cutting Metals, In 3 p. - Gorky, 1985. P. 1., 150 p.

[14] Podurayev, V. N. Cutting Hardly Processed Materials, Tutorial for Higher Education Institutions, Moscow, Higher School, 1994, 587 p. 